\title{
В.А. Еровенко
}

Аннотация. Статья посвящена улучшению понилания лекиий по мателатике на методологии университетской риторики. В ней обсуждается частная риторика, точнее, университетская риторика, относяшаяся $\kappa$ сббере "повышенной речевой ответственности" преподавания мателатики как когнитивного средства для улучшения мателатического лышиения в педагогике университетского мателатического образования. С точки зрения практической востребованности риторики в лекииях по курсу высшей мателатики, в работе выделяется тот раздел теории красноречия, который касается ритла речи в сочетании с точностью и сдержанностью при изложении материала, избегая при этол ненужного многословия. В такол контексте университетская риторика расслатривается в статье как когнитивное средство раскрепощения мателатического мышления студентов. По сути, хорошо "мыслить" на занятиях по высшей мателатике - значит, совершать в уле разнообразные интеллектуальные действия со сложныли математическили абстракиияли уже на новол понятийнол уровне, где средствал выражения отводится методологически обоснованная и даже ведущая роль при воздействии на адресата лекиии.

Ключевые слова: университетская риторика, проблела понилаемого красноречия, мателатическое образование.

\section{UNIVERSITY RHETORIC AS COGNITIV MEANS}

\section{OF LIBERALIZATION OF MATHEMATICAL THINKING}

\section{V.A. Erovenko}

Abstract. The article deals with the understanding of mathematics lectures on the methodology of university rhetoric. It discusses private rhetoric, or 
rather university rhetoric, related to the sphere of "increased speech responsibility" of teaching mathematics as a cognitive tool for improving mathematical thinking in the pedagogy of university mathematical education. From the point of view of practical demand of rhetoric in lectures on the higher mathematics course, the article highlights the section of the eloquence theory that deals with the rhythm of speech, accuracy and restraint in the presentation of material, while avoiding unnecessary multiple words. In this context, university rhetoric is seen in the article as a cognitive means of liberating students' mathematical thinking. In fact, it is good to "think" in classes in higher mathematics - it means to perform in mind a variety of intellectual actions with complex mathematical abstractions already at a new conceptual level, where the means of expression are given a methodologically sound and even leading role when affecting the recipient of the lecture.

Keywords: university rhetoric, the problem of understood eloquence; mathematical education.

У ниверситетская риторика, или «академическая риторика», это, по сути, наиболее известный способ красноречия, истоки которого восходят к периоду античности, когда античная риторика стала не только объектом, но и средством преподавания. Риторика как одно из важнейших качеств преподавателя высшей школы совмещает в себе не только понимаемое изложение лекционного материала, способствующее постоянному расширению кругозора, но и мастерство ораторского искусства, и культуру постановки научной речи в коммуникативном общении преподавателя со студентами. В таком контексте риторические способности преподавателя высшей школы становятся непременной составляющей его речевой культуры. Лекционное искусство преподавателя является одним из самых сложных, поэтому не случайно Сократ, с точки зрения критерия развитой «языковой личности», образно сказал: «Заговори, чтоб я тебя увидел». Однако если преподаватель практически не заботится о доступности восприятия студентамислушателями его лекций и не интересуется когнитивным речевым набором неформальной профессиональной аргументации, для него классический «риторический канон» остается вне его осознанной педагогической деятельности.

Следует отметить, что даже в философии науки сейчас обсуждается и осмысливается новая проблематика, связанная с «риторическим поворотом» в науке, которая отражается в таком интересном направлении философрских исследований, как "риторика науки», в частности, это относится и к риторике математики. В философии математики говорят о ней с точки зрения математической аргументации в образовании. «Как бы ни выглядела математическая деятельность со стороны, действующему-то математику она представляется внутренним диалогом с собой с иелью 
убедить в чел-то салого себя. В этом качестве математическая деятельность может, конечно, считаться своеобразной, назовем её внутренней, риторикой» [1, с. 3]. Лекционный монолог преподавателя математики - это в сущности процесс научного поиска, в котором студенты должны почувствовать свою сопричастность к нему. Если спроецировать сказанное на преподавание математики, то следует заметить, что поскольку академическая риторика должна быть максимально информативной и научно мотивированной, то понимание, даже еще не решение, математической задачи предполагает уже наличие определенных знаний у студента, то есть у того, кто использует математически точное описание.

Так, с целью доступности восприятия можно в начале лекции привести интересный мотивирующий пример для обоснования дальнейшего изложения новой темы. Вполне уместным может оказаться связанное с излагаемой темой юмористическое замечание, а для подчеркивания актуальности изучаемой темы и необходимости ее изучения можно задать хорошо продуманный мотивационный вопрос. По ходу лекции через процедуру собственной рефрлексии теоретического материала полезно приводить интересные нестандартные примеры, с помощью которых новая математическая информация запоминается лучше всего. Кроме того, с точки зрения когнитивной психологии восприятия сложной математической темы, опытный преподаватель при визуальном контакте с аудиторией понимает необходимость смены темпа речи, не только делая «мхатовские паузы» до и после важных утверждений, но и меняя при этом голосовую «тембральную насыщенность» сказанного лектором, повышая и понижая тон голоса для выделения смысловых акцентов. $\mathrm{C}$ точки зрения практической востребованности риторики в лекции по высшей математике, обязательно следует выделить в теории красноречия тот раздел, который касается ритма речи в сочетании с точностью и сдержанностью при изложении материала, избегая при этом ненужного многословия.

Перед университетским преподавателем высшей математики, хорошо владеющим излагаемым студентам профессиональным материалом, стоят следующие задачи: во-первых, сорормировать устойчивые навыки лекционной речи, направленные на практическое применение при решении реальных задач, адаптированных к будущей специальности студентов, а, во-вторых, сформировать способность к когнитивной рефлексии, чтобы с помощью риторического анализа читаемой лекции выявлять все те математические понятия и утверждения, которые были не поняты или не усвоены студентами. Проблема риторичности в математическом мышлении - это проблема поиска такого языка изложения, который способен «линилизировать» пассивность студента на лекиии. «Риторичность превращает фрразу, написанную с целью сообщить информацию с помощью риторических структур, во фрразу, написанную с целью вызвать рефлексивную реакцию реципиента на осваиваемую текстовую реальность» [2, с. 222]. Риторически выстроенное описание впервые воспринимаемого математического тек- 
ста должно еще обладать достаточным потенциалом понимания, например, когда при коротком описании системы с помощью матрицы возникает новая «категория мышления». Как мудро сказал Сергей Аверинцев: "Риторика - это не значит "говорить не то, что дулаешь"; это значит говорить то, что дулаешь тыл, но на языке тех, кто тебя слушает». По сути, риторика занимается речевой коммуникацией с помощью «риторических жанров» педагогического дискурса.

Существуют разные определения понятия «мышление». Под математическим мышлением понимается способность оперирования понятиями математического языка, специфика которого заключается в выделении множеств, замкнутых относительно какой-либо математической операции. Математическое мышление в основном опирается на дедукцию и индукцию, но в процессе изучения математики не менее важным средством понимания излагаемого материала являются «фигуры речи», основанные как на акцентированном употреблении математических понятий, так и на интерпретации их в переносном смысле. В таком контексте университетскую риторику можно рассматривать как когнитивное средство раскрепощения математического мышления студентов, так как «мыслить» на занятиях по математике - это значит, совершать в уме интеллектуальные действия с математическими абстракциями на новом понятийном уровне, где средствам выражения отводится методологически обоснованная ведущая роль при воздействии на адресата. Следует также отметить, что в совре- менных реалиях социокультурного общения риторику недостаточно рассматривать как мастерство эфрективной речи или как средство обучения, поскольку при более широком взгляде на эту дисциплину она является средством воспитания культуры мышления.

Сказанное выше означает, что, хотя мышление связано с функционированием мозга, способность мозга оперировать математическими абстракциями формируется в результате усвоения норм культуры, логики и языка. Практические приемы риторики преподавались уже в Древнем Риме, но если раньше риторика мыслилась как особая техника организации языка на основе принципов культуры и невербальных средств коммуникации, то в наше время она опять становится насущной образовательной потребностью. Не случайно мыслители прошлого подчеркивали востребованность образования, построенного не только на научной рациональности, но и на понимании важности риторики, опирающейся на апробированные образовательные традиции среди которых следует особо выделить «здравый смысл». Наиболее ярким представителем теоретической риторики являлся Цицерон, который не сомневался в полезности риторики. Будучи для римлян мудрым наставником, Цицерон выявил пять основных критериев успешной речи: inventio, нахождение подходящего материала для выступления; disposition, его продуманное расположение по ходу речи; dictio, характерный стиль для выступающего; actio, исполнение речи с нужным интонированием сложных мест; memoria, достижение смыслового запоминая и 
понимания [3, с. 115]. Главная сила речей Цицерона проявляется в их содержательности, логичном расположении материала и умении подбирать доходчивые и выразительные аргументы средств языка.

Напомним, что Цицерон образно говорил, что «поэтали рождаются, а ораторали становятся». Постоянная работа ораторов над умением выделять ключевые слова помогает им формировать речевое мышление. На первый взгляд, использование риторики в обучении математике, опираясь только на веские аргументы в доказательстве, может показаться нерациональным подходом, который чужд профессиональным математикам. Однако глубокое изучение той роли, которую риторика способна играть в такого рода образовательной методике, по сути, делает возможным ее практическое использование в усилиях, направленных на достижение понимания математики на всех уровнях ее преподавания. Для подтверждения сказанного укажем на риторические стили мышления, используемые в математической повседневной образовательной практике: во-первых, «дискурсивный» стиль, достоинством которого является последовательное четкое и ясное изложение, основанное на законах логики, но иногда утомляющее излишними подробностями; во-вторых, «интуитивный» стиль, отличающийся лаконичностью и даже иногда афористичностью, но именно поэтому не всегда может быть однозначно истолкован другими; в-третьих, «ассоциативный» стиль, когда ход мысли понятен говорящему и который правильно воспринимается хорошо подготов- ленными слушателями, но при злоупотреблении таким стилем изложения высшей математики студенты даже из правильных посылок все же могут делать ложные выводы.

Одним из первых фрилософров, выявлявших когнитивное начало в слове как носителе убеждения людей, был софист Горгий, который определял риторику как способность убеждать словом. Сам Горгий был выдающимся оратором, но он знаменит еще тем, что сформулировал следующие три главных положения или теоремы. Первая теорема гласит, что «ничто не существует", то есть нельзя доказать существование бытия, существование небытия и существование единого бытия и небытия; согласно второй теоремы, «ежели что и существует, то оно непознаваемо», то есть мышление отрывается от бытия, поскольку есть различие между существующим и мыслимым предметом; следуя третьей теореме, «если чтото познаваемо, то оно невыразило и неизъяснимо», то есть знание о существующем непередаваемо другим людям. При переводе этих положений на язык математики, непонятно чем занимается математики, совершенствуя свою интуицию, так как абстрактных математических объектов в мире не существует. В математике есть примеры утверждений, которые попадают под теоремы Горгия, хотя некоторые интуитивно неочевидные вопросы вполне естественно формулируются в ней. «Математики тренируют свою интуицию дальше, чтобы какие-то новые утверждения вдруг показались почему-то всем математикам интуитивно очевидными, и тогда их можно было бы принять в качестве новых аксиом в надежде, что с их по- 
мощью ответы на какие-то из таких вопросов могут быть получены» [4, с. 20]. Но несмотря на то, что, согласно Горгию, слово отлично от мысли, а мысль отлична от бытия, он предоставляет полную свободу слову.

В когнитивном контексте формирования математического мышления студентов, слушающих курс высшей математики, особый интерес представляет третья теорема Горгия, согласно которой если человек что-то доказал в современной математике, то это не значит, что он может математически понимаемо рассказать возможно очень «переусложненное доказательство», содержащее сотни страниц математического текста или использующее затратные по времени компьютерные вычисления, другому человеку. Согласно современной «риторики науки» знание отличается от веры тем, что оно не может быть ложным, поскольку тогда оно не является знанием. Горгий солидаризируется с Сократом в том, что риторика может репрезентировать убеждения, основанные на вере, так как хороший оратор может гипотетически убедить в чем угодно тех людей, которые не являются специалистами в рассматриваемой области. Кроме того, в математическом образовании трудно выделить риторический стиль мышления, так как всегда может возникнуть «проблема непонимания», которую только методологически опытные преподаватели рассматривают или трактуют как учебную ситуацию, которая требует когнитивных усилий для достижения понимания, когда каждый компонент математической лекции конструируется с помощью методических приемов, способствующих уси- лению ее понимания и убеждения в правильности сказанного. Однако риторическая наука с помощью интерактивных риторических приемов и культуры речи, рассматриваемых как необходимое условие эфрективного взаимодействия, предлагает разные варианты мотивировки студентов, слушающих университетский курс высшей математики.

Сложность взаимодействия преподавателя математики со студентами обусловлена еще тем, что курс высшей математики как правило читается на первом курсе, когда происходит адаптация студентов к университетской жизни и когда многим студентам еще надо «научиться учиться». В такой ситуации на лекциях по математике только на возможностях и пользе абстрактного мышления при полном отсутствии эмоциональности высказываемого и, как следствие этого, обеднение вспомогательного интонирования речи приводит при истинности математических конструкций к «риторической деградаиии» конкретной речевой ситуации, формально ограниченной только профессиональной сфрерой. «Кроме того, с точки зрения обоснования математики, проблема истины в математике заключаются в том, что, даже при точном определении языка математики, математические предложения, которые являются истинными либо ложными, или, во всяком случае, осмысленными в одном языке, могут быть бессмысленными выражениями в другом, например, естественном языке» [5, с. 45]. Педагогический артистизм преподавателя математики основывается на культуре, аргументированности, образности его речи и внутренней 
убежденности в истинности излагаемого. Риторическая окраска лекционного материала, позволяющая эмоционально воздействовать на слушателей, частично избавляющая их от «занудства» необходимой аргументации сложных математических рассуждений, является одной из важных составляющих профрессионализма преподавателя.

Энергия творческих намерений лектора, многократно читавшего стандартный программный материал по разделам математики, помогает ему каждый раз находить что-то методологически нестандартное и, по сути, открывать новое в уже давно известном. Даже «риторические уловки» понятийного мышления, характеризующие специальные приемы лекционного взаимодействия преподавателя со студентами, практически необходимы преподавателю математики, так как математические понятия исходят не из самой действительности, а из математического представления о ней с помощью готовых ассоциативных связей, опирающихся на предшествующий опыт сформированной математической культры студентов. Риторические приемы, соответствующие стилю изложения математического знания, то есть в контексте понимания математической аргументации, часто выступают как способы убеждения, способствующие «рождению смысла» математических высказываний в разуме студентов-слушателей. Это, в свою очередь, накладывает на преподавателя математики определенные требования, так как чтобы «красноречиво говорить» по какой-нибудь математической теме нужно полностью понимать ее. Об этом еще говорил сам Марк Туллий Цицерон, кото- рый утверждал: «Ораторское искусство нельслило, если оратор не овладел в совершенстве предлетол, о которол хочет говорить». Дисциплина мышления при анализе новых математических понятий иногда требует реального напряжения интеллектуального внимания, которое не всегда может выдержать на протяжении всей лекции плохо математически подготовленный студент.

Безусловно, среди преподавателей математики найдется немало скептиков по поводу целесообразности использования риторики в методике обучения высшей математике, однако ее практическое применение показывает, что университетская риторика является действенным когнитивным средством в формировании математического мышления, направленным на достижения понимания математики на различных уровнях математического образования. Некоторые специалисты понимают риторику в широком смысле как средство эфрфективной аргументации. Но несмотря на это четкое определение «категорий риторики» так и не было сорормулировано и систематизировано, поскольку смысл этих понятий существенно зависит от контекста, а введением понятия эфрфективности преподавания они пытаются подчеркнуть различие риторики и аргументации. «Исходной теоретической моделью, на основе которой строятся все теоретические концепции риторики, является взаимодействие мысли и слова. Соответственно, считается, что эффрективность воздействия риторических приемов на слушателей и читателей зависит от двух факторов: от содержания мысли и ее выражения в языке, которые в риторике считаются 
тесно взаимосвязанными» [6, с. 49]. В логике изложения математических утверждений аргументация представляет собой рациональное доказательство, соответствующее законам формальной логики, лекционная убедительность которого обеспечивается еще и качеством «риторической оболочки», позволяющей эвристически воздействовать на слушателя.

В гуманитарном знании используется другая логика и риторика, как способ организации коммуникативных средств, в которой вопросы аргументации в целях достижения взаимопонимания видятся совершенно иначе, когда понимаемая риторика для обеспечения доходчивости аргументации занимается средствами обоснования выдвинутых положений, поскольку ее предмет не истина, а правдоподобное мнение. Но поскольку в риторике аргументация воспринимается как специфический способ речевого воздействия на слушателя, то в ней допустимы как логический, так и психологический способы аргументации, если последний играет позитивную роль в речевом воздействии на сознание человека. Говоря об университетской риторике при изложении математического материала, лектор должен, в первую очередь, заботиться о воздействующей силе аргументов на студентов-слушателей и правильности их использования, а не о «иветах красноречия». Даже в математической лекции для качества риторического воздействия важно понимать, как можно использовать такие «изобразительно-выразительные» средства как метафора, сравнение или повтор, имеющие принщипиальное отличие от художественного текста в соответствии с авторским видением фррагментов темы, поскольку указанные методические средства понимаемого изложения вне математического контекста лекционного материала могут быть непонятны слушателям. Следует заметить, что методы когнитивного обучения математике позволяют использовать как рациональные начала, так и психологические начала умственных способностей для целостного восприятия проблемных ситуаций, естественно возникающих при изучении математики.

Когнитивный подход при раскрепощении математического мышления требует еще и особого методологического внимания к инструментальной сфрере системы образования, с учетом социальных факторов обучения при решении проблемно-ориентированных прикладных и теоретических учебных математических задач, мысленно отражающих математическую деятельность по постижению идеальных сущностей. Заметим, что «когнитивная педагогика» философии математического образования отражает взгляд на студента как на человека, познающего специально организованную систему практических знаний, требующих опоры в процессе аргументации на математические умозаключения. «Основная цель аргументации, как известно, - присоединение аудитории к положениям оратора, которое возможно благодаря одинаковой разумности всех людей, различающихся лишь силой ума» [7, с. 46]. Образцом аргументации являются приемы формального математического рассуждения, благодаря анализу которых сформировалась концепция формальной логики, хотя изучение аргументации в гуманитарных науках полно- 
стью не раскрывает проблемы психологической и социологической специфики аргументации. Поэтому в последнее время активизировался интерес к когнитивной составляющей методологической интерпретации проблемного процесса приложений математических теорий. Наиболее ярко специфика математического мышления студентов проявляется в том, что приложение и применение математики является когнитивно-технической деятельностью.

Когнитивная действенность риторических приемов на лекциях по математике может быть продемонстрирована на примере профессионально значимых и в тоже время неформальных ситуаций общения преподавателя со студентами. Но учитывая фрактор подготовленности конкретного адресата речи, цель и задачи математической лекции, а также тональность и обстановку аудиторного общения, ссылки на теорию риторики явно недостаточно для обоснования права повсеместного использования методологических подходов, реализуемых в университетской риторике, на всех проблемных лекциях различной сложности. Например, учитывая природную тембральную окраску голоса, для заинтересованных слушателей имеет значение темп и громкость речи. Поэтому, с точки зрения «педагогической риторики», в течении лекции преподавателю необходимо постоянно работать над дикцией при смене темпа речи с целью доступного изложения смысловой сути математического утверждения. Римский филоcoфp и поэт Луций Сенека говорил: «Oратор не тот, кто охотно говорит сал, а тот, кого приятно слушаты». Но университетскую лекцию по математике не всем «приятно слушать». Она отличается тем, что в ней есть логическая составляющая, и с точки зрения логики изложения даже «тяжеловесной лекции» все ее определения «риторически выстроены» в соответствии с тем, где и как будут использованы вводимые математические понятия. А поскольку новый язык математики и правила его применения могут быть на лекциях отдалены по времени друг от друга, то университетская риторика математического образования как когнитивное средство процесса понимания, запоминания и умения анализировать поможет заранее осмыслить практическое содержание терминов и понятий.

В заключение особо отметим, что точность и строгость аргументации математического знания вполне совместима с благожелательным и профессионально умелым «риторически наполненным» общением со студентами. В истории математического образования настойчиво проглядывается «прошлое в настоящем», поэтому в инновационных способах изложения математики, даже для «неспособных к математике», должна быть доля компромисса как невидимая черта или «мера допустимого» при использовании новой категории мышления, сохраняя при этом «социальный оптилизл» и свободу обучаемых. В контексте раскрепощения математического мышления риторика выступает не только в качестве эфрфективной аргументации как доказательности речи, но еще и «методологией убеждения» на пути коммуникативного успеха в студенческой аудитории. В памяти остаются прежде всего те преподаватели, которые выделяются своей харизмой и эмоционально-интеллектуальной культу- 
рой умения общаться со всеми студентами, а также с хорошими риторическими способностями и нужными профессиональными навыками. Однако хорошее владение университетской риторикой, раскрепощающей математическое мышление студентов, - это не только природный талант преподавателя, но еще и результат его тщательной сознательной подготовки.

\section{СПИСОК ИСТОЧНИКОВ И ЛИТЕРАТУРЫ}

1. Самохвалов, К.Ф. О математической деятельности как риторике // РАЦИО.ru. 2011. № 5. С. 3-10.

2. Горобеи, Л.Н. Риторические жанры педагогического дискурса // Известия Российского государственного педагогического университета им. А.И. Герцена. 2008. № 62. С. 219-225.

3. Еровенко, В.А. Философия образования Цицерона и место риторики в преподавании математики // Российский гуманитарный журнал. 2017. Т. 6. № 2. С. 109-119.

4. Фон-Дер-Флаасс, Д.Г. Теоремы софиста Горгия и современная математика // Квант. 2010. № 5. С. 16-23.

5. Михайлова, Н.В. Понятие истинности математической теории в контексте обоснования современной математики // Российский гуманитарный журнал. 2017. Т. 6. № 1. С. 40-47.

6. Пигалев, А.И. Философия риторики и принципы культуры // Мир психологии. 2017. № 4. C. 48-61.

7. Кащей, Н.А. Современная риторика как методология убеждения // Вестник Новгородского государственного университета. 2012. № 67. С. 45-48.

\section{REFERENCES}

1. Erovenko V.A. Filosofiya obrazovaniya Cicerona i mesto ritoriki v pre-podavanii matematiki, Rossijskij gumanitarnyj zhurnal, 2017, vol. 6, no. 2, pp. 109-119. (in Russian).

2. Fon-Der-Flaass D.G. Teoremy sofista Gorgiya i sovremennaya matematika, Kvant, 2010, no. 5, pp. 16-23. (in Russian).

3. Gorobec L.N. Ritoricheskie zhanry pedagogicheskogo diskursa, Izvestiya Rossijskogo gosudarstvennogo pedagogicheskogo universiteta im. A.I. Gercena, 2008, no. 62, pp. 219-225. (in Russian).

4. Kashchej N.A. Sovremennaya ritorika kak metodologiya ubezhdeniya, Vestnik Novgorodskogo gosudarstvennogo universiteta, 2012, no. 67, pp. 45-48. (in Russian).

5. Mihajlova N.V. Ponyatie istinnosti matematicheskoj teorii v kontekste obosnovaniya sovremennoj matematiki, Rossijskij gumanitarnyj zhurnal, 2017, vol. 6, no. 1, pp. 40-47. (in Russian).

6. Pigalev A.I. Filosofiya ritoriki i principy kultury, Mir psihologii, 2017, no. 4, pp. 48-61. (in Russian).

7. Samohvalov K.F. O matematicheskoj deyatelnosti kak ritorike, RACIO.ru, 2011, No. 5, pp. 3-10. (in Russian).

Еровенко Валерий Александрович, доктор физико-математических наук, профессор, кафедра общей математики и информатики, Белорусский государственный университет, erovenko@bsu.by

Erovenko V.A., ScD in Physics and Mathematics, Professor, General Mathematics and Informatics Department, Belarusian State University, erovenko@bsu.by 